\title{
The Water and Energy Budget of the Arctic Atmosphere
}

\author{
Tido SEMmler* AND Daniela JacoB \\ Max Planck Institute for Meteorology, Hamburg, Germany \\ K. HeINKE SCHLÜNZEN \\ Meteorological Institute, University of Hamburg, Hamburg, Germany \\ RALF PODZUN \\ Max Planck Institute for Meteorology, Hamburg, Germany
}

(Manuscript received 11 December 2003, in final form 17 July 2004)

\begin{abstract}
The Arctic plays a major role in the global circulation, and its water and energy budget is not as well explored as that in other regions of the world. The aim of this study is to calculate the climatological mean water and energy fluxes depending on the season and on the North Atlantic Oscillation (NAO) through the lower, lateral, and upper boundaries of the Arctic atmosphere north of $70^{\circ} \mathrm{N}$. The relevant fluxes are derived from results of the regional climate model (REMO 5.1), which is applied to the Arctic region for the time period 1979-2000. Model forcing data are a combination of 15-yr European Centre for MediumRange Weather Forecasts (ECMWF) Re-Analysis (ERA-15) data and analysis data. The annual and seasonal total water and energy fluxes derived from REMO 5.1 results are very similar to the fluxes calculated from observational and reanalysis data, although there are some differences in the components. The agreement between simulated and observed total fluxes shows that these fluxes are reliable. Even if differences between high and low NAO situations occur in our simulation consistent with previous studies, these differences are mostly smaller than the large uncertainties due to a small sample size of the NAO high and low composites.
\end{abstract}

\section{Introduction}

The Arctic, defined here as that part of the globe that is north of $70^{\circ} \mathrm{N}$, is one of the sinks for atmospheric energy within the global climate system (Nakamura and Oort 1988, hereafter NO88). While the incoming solar radiation is small, energy is advected from midlatitudes to the north. Thus the Arctic plays a major role in the global circulation. Because of its hard climate conditions, the Arctic is a region that is not as well explored as other regions of the world. The Arctic is supposed to

\footnotetext{
* Current affiliation: Met Eireann, Dublin, Ireland.
}

Corresponding author address: Dr. Tido Semmler, Met Eireann, Glasnevin Hill, Dublin 9, Ireland.

E-mail: tido.semmler@met.ie be very sensitive to possible global climate changes (Polar Group 1980; Barry et al. 1993). Thus it is very important to understand the processes in the Arctic atmosphere and its function within the global circulation.

There are previous investigations about both the water and the energy budget already (e.g., Serreze et al. (1995), Cullather et al. (2000), and Groves and Francis (2002) for the water budget and NO88, Overland and Turet (1994, hereafter OT94), and Overland et al. (1996) for the energy budget). Also the influence of atmospheric large-scale patterns like the North Atlantic Oscillation (NAO), the Arctic Oscillation (AO), and the North Pacific Oscillation (NPO) on the Arctic atmospheric water and energy budget has been studied (Hurrell 1995; Dickson et al. 2000; Adams et al. 2000; Rogers et al. 2001; Groves and Francis 2002).

Serreze et al. (1995) used rawinsonde observations to determine the change of total water content of the at- 
mosphere north of $70^{\circ} \mathrm{N}$ as well as moisture fluxes across $70^{\circ} \mathrm{N}$. They estimate precipitation minus evaporation $(P-E)$, which is the water flux to the surface, as a residuum. Cullather et al. (2000) used reanalysis data from the European Centre for Medium-Range Weather Forecasts (ECMWF) and from the National Centers for Environmental Prediction-National Center for Atmospheric Research (NCEP-NCAR) to determine moisture fluxes into the Arctic basin. There are regional differences in the lateral moisture fluxes in the Greenland-Baffin Island region between the two studies, which, however, do not affect the value averaged over the whole $70^{\circ} \mathrm{N}$ circle substantially. Even if it is difficult to decide which moisture fluxes are more reliable, there is some evidence according to Cullather et al. (2000) that the differences are due to deficiencies in the rawinsonde network and that the reanalysis data may be a more sophisticated synthesis of the rawinsonde data than the method employed by Serreze et al. (1995).

Since precipitation and evaporation are variables from the forecast system of the reanalysis centers and are not directly assimilated with observations, they contain a possible model drift. Thus the resulting $P-E$ values are not as reliable as the calculated moisture fluxes. Both the ECMWF and the NCEP numerical prediction models give lower values for $P-E$ than the moisture convergence would suggest. This means that there is indeed a model drift toward drier conditions in both models and that the water budget is not closed if using forecast $P-E$ and calculated moisture convergence. Thus Cullather et al. (2000) use the calculated moisture convergence values to produce regional average $P-E$ distributions assuming that the total atmospheric water content is constant. Since this assumption is only true if looking at annual means, this method does not allow us to study the annual cycle of $P-E$. Groves and Francis (2002) combine the water content in the Arctic atmosphere retrieved from the Television Infrared Observation Satellite (TIROS) Operational Vertical Sounder (TOVS) with the winds from NCEP reanalyses to calculate not only the moisture convergence but also the total water content of the atmosphere. Using the changes of total water content, it is indeed possible to calculate the annual cycle of $P-E$ as a residuum like Serreze et al. (1995) did on the basis of rawinsonde observations.

NO88 used satellite and rawinsonde observations to calculate the change of total energy in the Arctic atmosphere north of $70^{\circ} \mathrm{N}$, the radiation flux at the top of the atmosphere, and the energy flux across $70^{\circ} \mathrm{N}$. They calculated the energy flux at the surface as a residuum. Using the same methods as NO88, OT94 extended the climatology of the energy budget to a time period of 25 yr. This extension did not change the results substantially. Overland et al. (1996) extended the analysis beyond the $70^{\circ} \mathrm{N}$ circle and qualitatively described the latitudinal and longitudinal structure of the energy flux convergence over the Arctic. Adams et al. (2000) looked at the changes of the components of the Arctic heat budget during the transition between summer and winter using reanalysis data from NCEP-NCAR. Like $P-E$, the surface energy fluxes from reanalyses are forecast variables with a reduced reliability.

Most of these studies report problems in determining the surface fluxes, if they include them. Problems arise either because they have to be calculated as residuum values from observational data, thus adding uncertainties, or because they are forecast variables underlying a model drift if using reanalysis data.

Whereas previous studies (Dickson et al. 2000; Rogers et al. 2001) found a clear dependence of the Arctic moisture budget on the NAO and the AO, two largescale circulation patterns closely linked to each other (Rogers et al. 2001), the influence from the AO on the energy budget seems to be relatively small (Adams et al. 2000). The largest influences on the water budget can be seen in the southern Greenland and northern North Atlantic regions, but also when averaged over the whole Arctic basin, influences can be detected.

The main objective of this study is to reduce the uncertainty of the water and energy fluxes from the surface, the midlatitudes, and the stratosphere into the Arctic tropospheric atmosphere. The fluxes are determined as climatological annual and seasonal means as well as composites of the model results with respect to the NAO.

The investigations are carried out with the regional climate model (REMO 5.1; Jacob et al. 1995; Jacob and Podzun 1997), which has already been successfully used to simulate the water budget of the Baltic Sea drainage basin (Jacob 2001; Jacob et al. 2001). A description of the model and comparisons with measured data for single case studies in the Fram Strait region are given in Semmler et al. (2004).

In contrast to observations, which can be biased by local effects, and to global climate models and reanalyses with their coarse resolution, a regional climate model is able to resolve mesoscale structures. Even if averaging the highly resolved regional climate data over larger areas, the high resolution is useful, because more atmospheric processes are simulated explicitly. These additional processes can lead to different results compared to coarser global climate model data. Even if a regional climate model bears its own uncertainties, the atmosphere is constrained to a state close to the observed one via the lower and lateral boundary values, 
which is not the case for a global climate model. The atmospheric winds, moisture, and temperature, as well as the surface pressure used to drive the regional climate model from reanalysis data, have a comparably good reliability, since they are assimilated with observation data. According to Cullather et al. (2000), the reanalyzed moisture and wind fields are an elaborate synthesis of the available rawinsonde data, whereas the surface fluxes from the reanalyses are not as reliable, since they are derived from the forecast systems of the reanalysis centers underlying systematic errors due to model spinup. Thus the water and energy budget is not closed using reanalysis data, whereas this is the case in REMO 5.1 except for the outermost eight grid boxes, where the lateral boundary conditions are assimilated. A possible model spinup is negligible since the climate model is only initialized once in the beginning of the long time period, whereas the forecast from the reanalysis centers is initialized every $6 \mathrm{~h}$. A regional climate model provides the possibility of getting a consistent high-resolution dataset of all variables that are important for the water and energy budget.

In section 2 of this paper, the model and case setup, as well as reasons for selecting the boundary data, are given. A comparison of the REMO 5.1 simulation results with observations from the Arctic Meteorology and Climate Atlas (AMAP; Fetterer and Radionov 2000 ) is given in section 3. Section 4 contains the REMO 5.1 results for the climatological mean annual and seasonal water and energy fluxes. The calculated fluxes are compared with the ones given in previous studies. Section 5 deals with the dependence of the fluxes on the NAO. In section 6, conclusions are drawn.

\section{Model setup and evaluation of boundary data}

It is difficult to decide where the boundaries of the Arctic region are to be located, because there are several definitions. According to the astronomical definition, all areas north of the Arctic circle $\left(66.5^{\circ} \mathrm{N}\right)$ belong to the Arctic (Wagner 1912). Alissow (1954) defines the Arctic as the region where the Arctic air mass is predominating in all seasons. According to Martyn (1992), the southern boundary of the Arctic over land is the tundras. Over sea, all regions with Arctic water masses belong to the Arctic. In this study, the Arctic is defined as the region north of $70^{\circ} \mathrm{N}$. Using this definition, it is possible to compare the REMO 5.1 results with the results from several previous studies.

The model domain used for the simulation contains the entire Arctic north of $70^{\circ} \mathrm{N}$, that is, parts of North America, central and northern Europe, Siberia, and the corresponding parts of the related oceans (Fig. 1). In

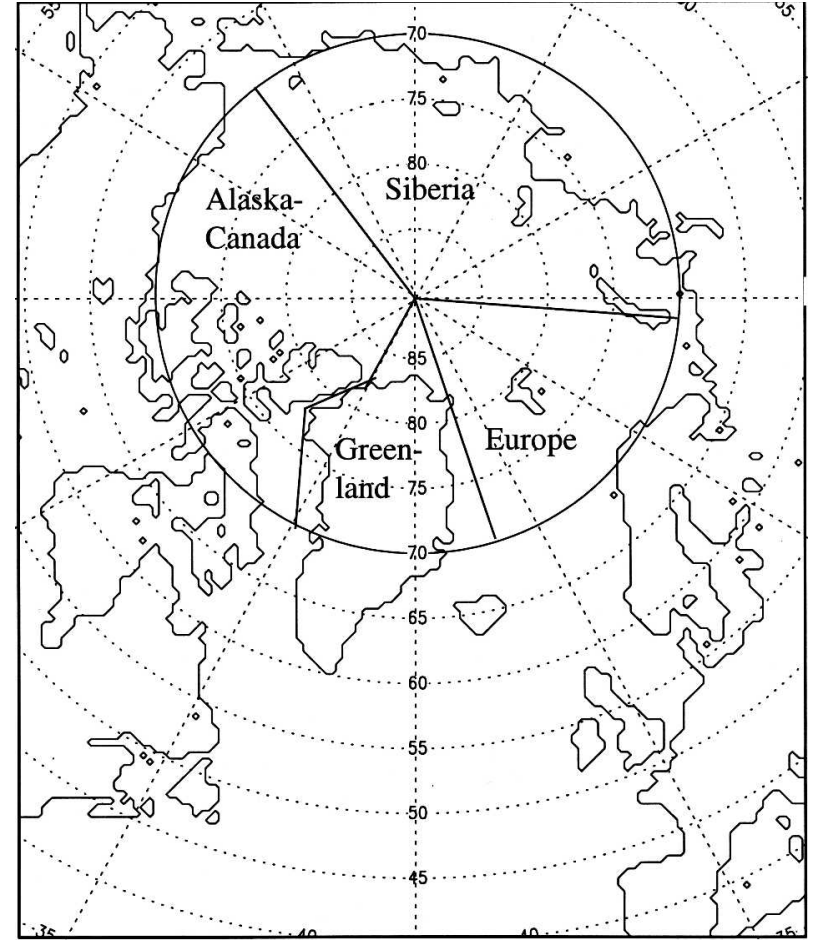

FIG. 1. Simulation domain and subdomains.

the Siberian region, the boundary of the model domain is quite close to $70^{\circ} \mathrm{N}$, whereas the distance between the model boundary and $70^{\circ} \mathrm{N}$ is much larger in the North Atlantic region. Thus, in the Siberian region, the simulation of the water and energy fluxes is influenced by the boundary values of the reanalyses stronger than in other regions. This choice of the model domain was made for several reasons: Serreze et al. (1995) and Groves and Francis (2002) have shown that the lateral fluxes are small in the Siberian region compared to the North Atlantic region with its cyclone activities. In the continental Siberian region, where the lateral boundary is located close to $70^{\circ} \mathrm{N}$, there are more observation stations than in the North Atlantic, where the lateral boundary is far away from $70^{\circ} \mathrm{N}$. It is more important to have a development relatively independent of the nearly pure reanalysis model output in the data-sparse and main contributive North Atlantic area than in the continental Siberian region, which has better data coverage and, in addition, does not influence the water and energy budget very strongly. In addition to the lateral fluxes, the fluxes at the surface and at the model top influence the water and energy budget. For the surface only, the lower boundary values sea surface temperature and sea ice cover are taken from the reanalyses; the surface fluxes themselves are still calculated within the model using the model-simulated near-surface at- 
mospheric temperature, moisture, and wind distributions, which can differ from those of the reanalyzed data. Since the surface fluxes from the reanalyzed data suffer from systematic errors leading to a nonclosure of the water and energy budget and since it is only possible to calculate total surface fluxes but not single components of the surface fluxes as residuum values, the reanalyses themselves are not sufficient for this study.

A rotated coordinate system is chosen to avoid strongly irregular grid cells in the polar region. The equator of this coordinate system follows the longitude at $30^{\circ} \mathrm{W}$ and $150^{\circ} \mathrm{E}$. The rotated North Pole is located at the equator at $60^{\circ} \mathrm{E}$. The horizontal resolution is $1 / 2^{\circ}$ corresponding to a roughly $55-\mathrm{km}$ grid resolution. The model domain consists of $145 \times 121$ grid points and 20 vertical levels. The uppermost level is located at $25 \mathrm{hPa}$. The model is run with a time step of $300 \mathrm{~s}$.

The simulation has been initialized for 1 January 1979 and then continuously run until 1 April 2001. This length of the simulation allows climatological investigations. The simulation period includes winters with high and low NAO indexes to study the influence of the NAO on the water and energy budget of the Arctic atmosphere. For this purpose, the NAO index according to Jones et al. (1997) is used. They defined the index as difference between the normalized pressures of Gibraltar and Reykjavik. The normalization prevents the stronger influence of Reykjavik on the NAO index, which would arise because of a higher standard deviation of the pressure in Reykjavik compared to Gibraltar. The NAO index as a mean over December-March according to Jones et al. (1997) is presented for the years 1950-2001 in Fig. 2.

The lower and lateral boundary values needed by the model are taken from the 15-yr ECMWF Re-Analysis (ERA-15; Gibson et al. 1997) for January 1979 to February 1994 and from ECMWF analyses for March 1994 to March 2001, although the NCEP-NCAR reanalyses (NCEP1; Kalnay et al. 1996) and the NCEP-Department of Energy (DOE) Atmospheric Model Intercomparison Project II (AMIP-II) reanalyses (NCEP2; Kanamitsu et al. 2002) cover a longer time period than ERA-15. However, the combination of ECMWF reanalyses and analyses allows a simulation of more than 20 yr. The simulation does not show an inconsistency due to the change from ECMWF reanalyses to analyses.

The reason for using ECMWF data is that ERA-15 data are closer to observations in the Arctic region than NCEP1 and NCEP2 if comparing parameters relevant to the atmospheric water and energy budget. Figure 3 shows the annual cycle of downward shortwave radiation from ERA-15, NCEP1, NCEP2, and gridded ob-

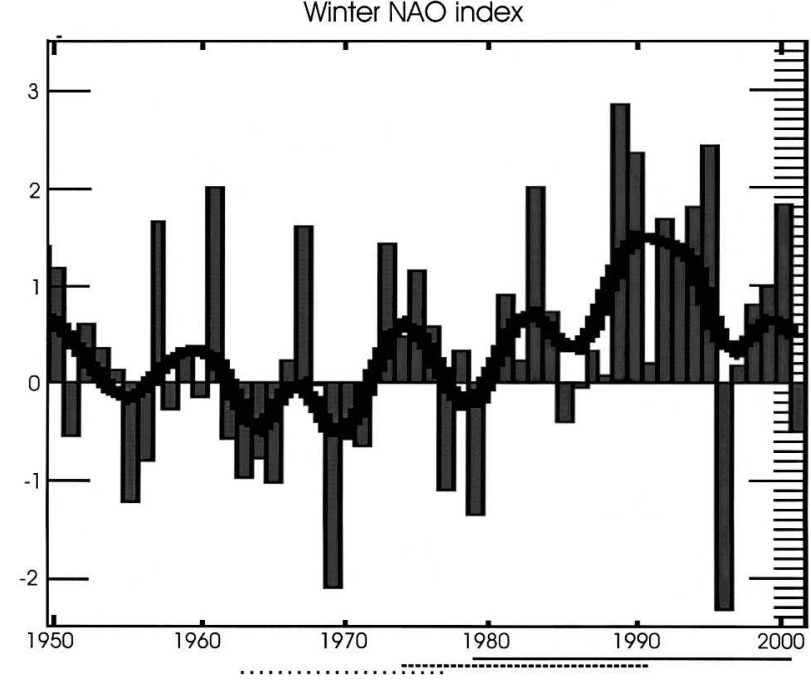

FIG. 2. NAO index according to Jones et al. (1997) from 1950 to 2001 as a mean over Dec-Mar. The solid line below the graphics indicates the time period of the REMO 5.1 simulation, the dashed line represents the measurements used in Serreze et al. (1995), and the dotted line represents the measurements used in NO88.

servation data from AMAP (Fetterer and Radionov 2000), averaged over the area north of $70^{\circ} \mathrm{N}$.

The AMAP downward shortwave radiation data are only available as climatological mean values from sparse measurements carried out between 1953 and 1999. The method to derive the radiation climatology is described in Serreze et al. (1998). Data from Russian North Pole and U.S. drifting stations, land stations, and several field campaigns in the Arctic Ocean and on land areas are included. Over the North Atlantic and for coastal Greenland, it was necessary to use calculated values because of a very poor data coverage. This has to be considered in the comparison of these data with averages over the time period 1979-93 from ERA-15, NCEP1, and NCEP2.

There is a strong overestimation of downward shortwave radiation in NCEP1 and NCEP2 by up to 100 (NCEP1 in July) and $70 \mathrm{~W} \mathrm{~m}^{-2}$ (NCEP2 in June), whereas the values are realistic in ERA-15. Even if the downward shortwave radiation is a parameter from the reanalysis forecast system and thus not directly assimilated with observations, these strong deviations from the observations in NCEP1 and NCEP2 compared to the good representation of this parameter in ERA-15 give a hint that there might be problems with the representation of the liquid water content in the Arctic atmosphere in NCEP1 and NCEP2. Indeed investigations from Serreze and Hurst (2000) and Hagemann and Dümenil-Gates (2001) show that the hydrological cycle in the Arctic is better represented in ERA-15 than 


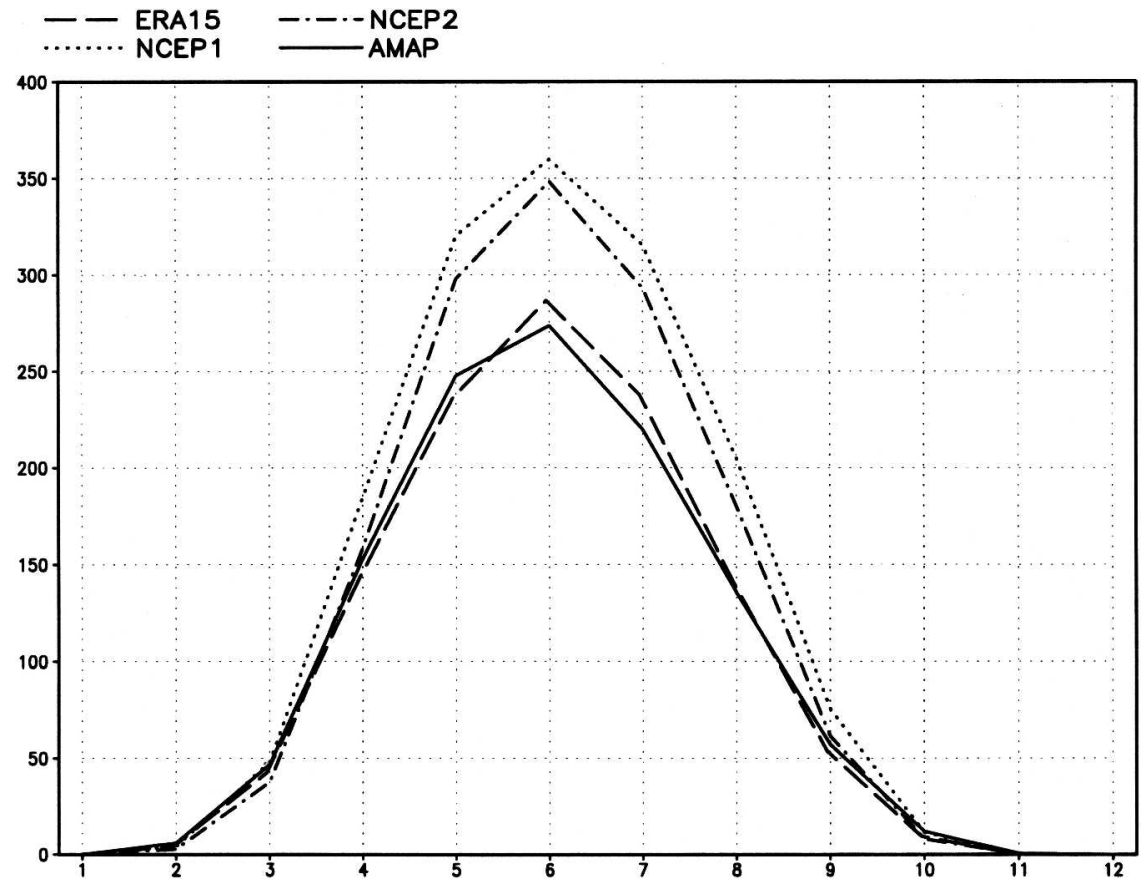

FIG. 3. Annual cycle of downward shortwave radiation in $\mathrm{W} \mathrm{m}^{-2}$ north of $70^{\circ} \mathrm{N}$ from ERA-15, NCEP1, NCEP2, and AMAP. Time period for ERA-15, NCEP1, and NCEP2 is 1979-93; for AMAP, it is 1953-99.

in NCEP1. Kalnay et al. (1998) report a problem with the NCEP1 humidity fields: there are spurious moisture sources and sinks resulting from the application of a poor diffusion approximation.

From the ECMWF reanalyses and analyses, respectively, 6-hourly values for the prognostic variables' temperature, water vapor, liquid water, the horizontal wind components in all model levels, and the surface pressure are used in the lateral boundary zone and the sea surface temperature at the lower boundary to drive the regional model. Data from the Scanning Multichannel Microwave Radiometer (SMMR) of the satellite Nimbus-7 and from the Special Sensor Microwave Imager (SSM/I) of the satellites $F 8, F 11$, and $F 13$ are used to prescribe the sea ice distribution at the lower boundary.

\section{Climatological evaluation of REMO 5.1 for the Arctic}

The evaluation is carried out for the annual cycles of four basic meteorological parameters against observations from AMAP (Fetterer and Radionov 2000): downward shortwave radiation, 2-m temperature, precipitation, and snow height over land. To do this, the Arctic has been subdivided into four regions: AlaskaCanada, Siberia, Europe, and Greenland (Fig. 1). Land and sea regions are considered separately. REMO 5.1 results and observations are averaged over all grid points included in the considered subregion. Figures 4-7 show results of this comparison. The snow height is only compared in the three land regions, AlaskaCanada, Siberia, and Europe, because snow is not explicitly simulated in REMO 5.1 over sea ice and over glaciers.

The climatological downward shortwave radiation from AMAP, which contains measurements between 1953 and 1999, is compared with the REMO 5.1 results for the whole simulated period except for the last three months. Thus, only complete years from the simulation are considered and the period lasts from 1979 to 2000. In all regions, the downward shortwave radiation seems to be strongly underestimated in the REMO 5.1 simulation results with maximum differences reaching about $50 \mathrm{~W} \mathrm{~m}^{-2}$ in late spring (Fig. 4). Over land this parameter is in all other seasons quite well simulated, whereas over sea the underestimation holds for all seasons. This underestimation of downward shortwave radiation shows that there might be problems with the representation of atmospheric water content in the REMO 5.1 simulation.

Although the downward shortwave radiation is underestimated in the late spring, the 2-m temperature rises too early in most areas (Fig. 5). Exceptions are the land areas of Greenland and Europe. This is not nec- 

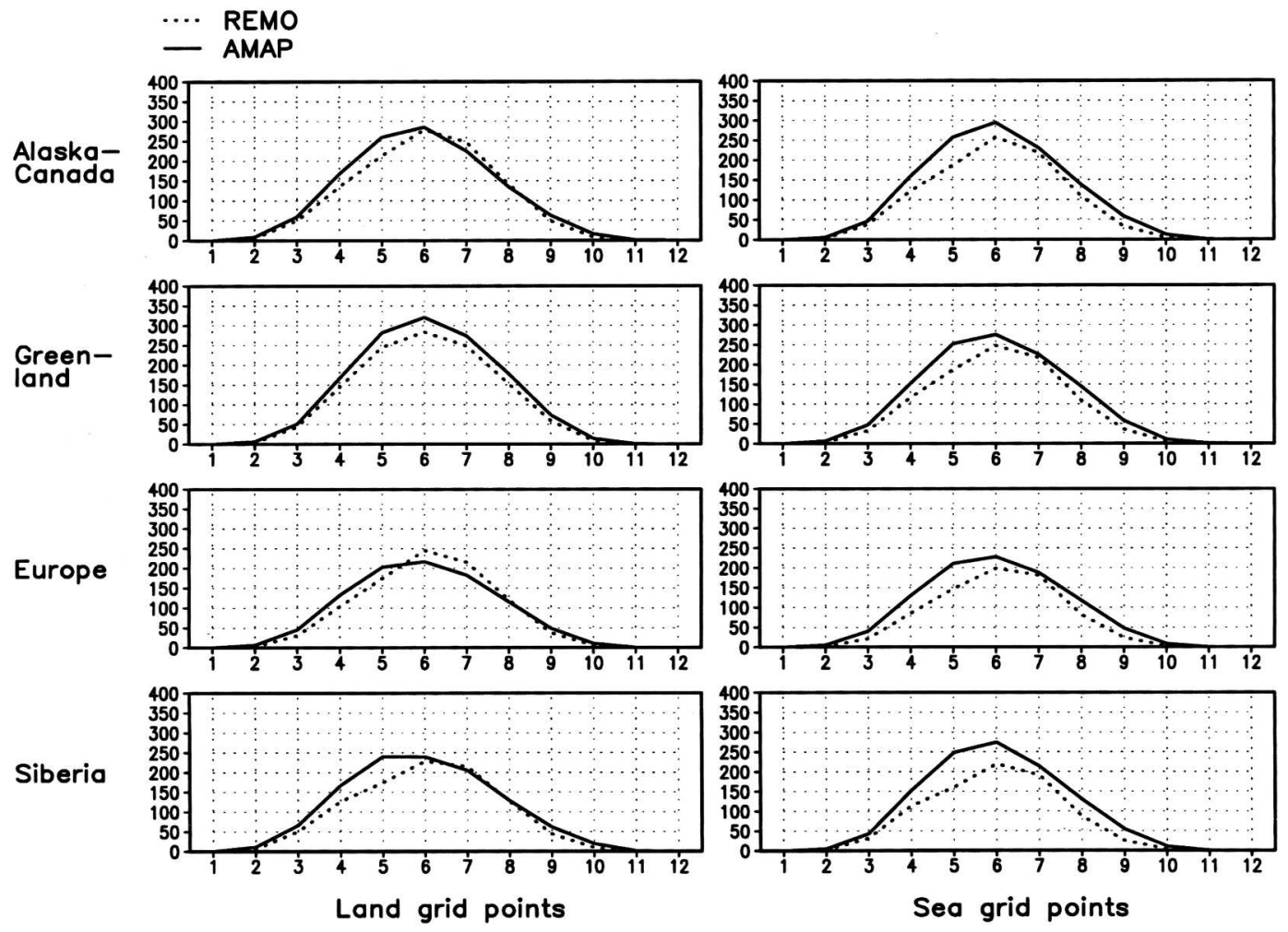

FIG. 4. Annual cycle of downward shortwave radiation in $\mathrm{W} \mathrm{m}^{-2}$ from REMO 5.1 and AMAP. Time period for REMO 5.1 is 1979-2000, and time period for AMAP is 1953-99.

essarily a contradiction because the downward shortwave radiation is only a part of the radiation budget at the surface. Furthermore, there is no correction for the different heights for which the model grid points and the observation grid points are representative. Corrections could not be done as a result of lacking information in AMAP. Since the 2-m temperature from AMAP is only available as a decadal mean for 1981 to 1990 , the REMO 5.1 simulation results have been averaged for the same time period. The basis for the gridded AMAP temperature fields are analysis fields of the International Arctic Buoy Program/Polar Exchange at the Sea Surface (IABP/POLES) for the Arctic Ocean and synoptic observations collected from the Global Telecommunications System by NCEP for land regions.

Similar to the downward shortwave radiation, there are only very sparse measurements of precipitation. The data used for creating the gridded fields are corrected gauge data from North Pole drifting stations and Canadian and Eurasian land stations. The undercatchment in blowing snow conditions can exceed $100 \%$ and is very dependent on the gauge type and the location of the gauge (Groisman et al. 1991); therefore the uncertainty of Arctic precipitation measurements is very large. Furthermore, the high spatial variability of pre- cipitation cannot be resolved by the sparse measurements. The precipitation climatology for 1950-99 from AMAP is compared with the REMO 5.1 results for a 1979-2000 climatology. The annual cycles of precipitation, which are different from region to region, are generally well represented in the simulation (Fig. 6), but there are significant differences between observations and the simulation in Europe. Here REMO 5.1 simulates more precipitation than observed in winter and less in summer. The land fraction in the European Arctic region is very small (Fig. 1), and over the European Arctic Ocean there are few observations. Only north of $85^{\circ} \mathrm{N}$ is the density of the North Pole drifting stations sufficient. Thus the comparison may not be representative for this region. The annual cycles of precipitation can be characterized as follows: In Greenland and Europe, the minimum of precipitation is observed and simulated in spring or early summer and the maximum is in autumn or early winter. In Alaska-Canada and Siberia, the precipitation minimum is in late winter or early spring and the maximum is in late summer or early autumn.

For the snow depth over land, the density of the measurement stations is comparably high. Five different datasets are used (Fetterer and Radionov 2000). 

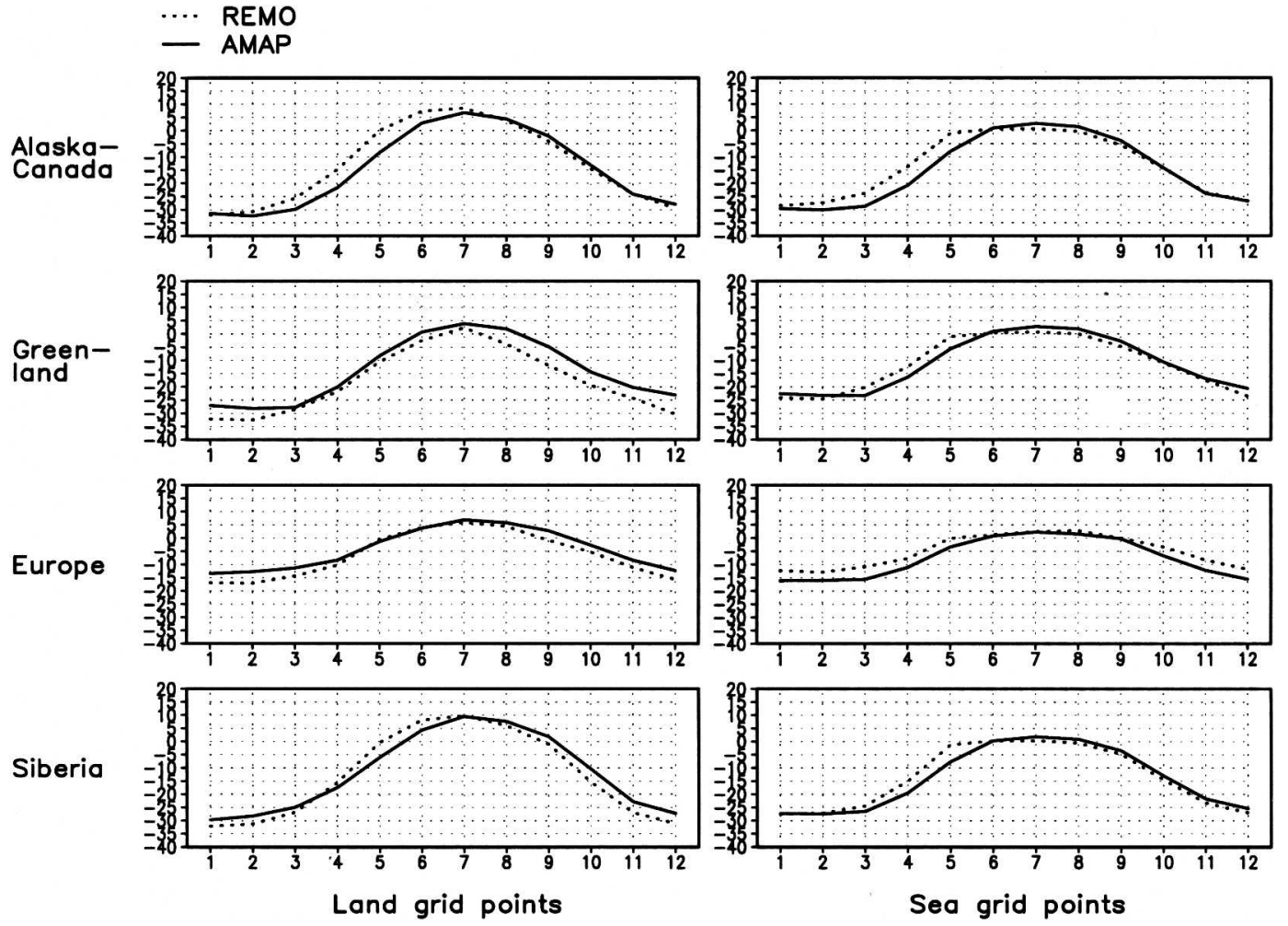

FIG. 5. Annual cycle of 2-m temperature in ${ }^{\circ} \mathrm{C}$ from REMO 5.1 and AMAP. Time period is 1981-90.

The overlap time period of these five datasets is 196682 , but also other years are included to compute the climatological values. These values are compared with REMO 5.1 results from 1979 to 2000. As for precipitation, the annual cycle of snow height over land is quite well represented (Fig. 7). The snowmelt starts too early in all three considered regions, which is consistent with the too-early increase of the 2-m temperature. The amount of snow is a little high in Alaska-Canada and Siberia in winter but somewhat too small in Europe.

The comparison between observations and the REMO 5.1 simulation shows that REMO 5.1 simulates all variables in the same range as measured. REMO 5.1 captures the annual cycle of precipitation reasonably well in all regions. Snow height and temperature are well simulated except for spring, when the temperature rises too early and the snow melts too fast. The underestimation of the incoming shortwave radiation in the late spring could be connected to problems with the simulation of the atmospheric water content and needs to be further investigated. First experiments with an additional prognostic equation for the cloud ice content instead of diagnosing the cloud ice content from the temperature show some improvements in the simulation of the incoming shortwave radiation.

\section{Climatological water and energy budget}

All water and energy fluxes at the uppermost model level located at $25 \mathrm{hPa}$ (hereafter top of the atmosphere), across the lateral boundary at $70^{\circ} \mathrm{N}$ and at the surface north of $70^{\circ} \mathrm{N}$, are determined by applying REMO 5.1. There is no water flux at the top of the atmosphere. The energy flux at the top is given by the sum of longwave and shortwave radiation budgets. At the surface, precipitation and evaporation account for the water budget. Longwave and shortwave radiation, sensible and latent heat flux, and the energy used for melting snow determine the energy budget. At the lateral boundary, the transports of water vapor and liquid water are relevant for the water flux $F_{W}$ and the transports of sensible and latent heat, as well as potential and kinetic energy for the energy flux $F_{E}$.

The lateral fluxes are calculated as follows:

$$
\begin{aligned}
F_{W}= & \iint \frac{}{\left(v q_{v}\right)} \frac{d p}{g} d x+\iint \frac{d p}{\left(v q_{w}\right)} \frac{d p}{g} d x, \\
F_{E}= & \iint_{p}(\overline{v T}) \frac{d p}{g} d x+\iint L\left(\overline{v q_{v}}\right) \frac{d p}{g} d x \\
& +\iint g(\overline{v z}) \frac{d p}{g} d x+\iint \frac{1}{2}\left(\overline{v|\mathbf{v}|^{2}}\right) \frac{d p}{g} d x,
\end{aligned}
$$



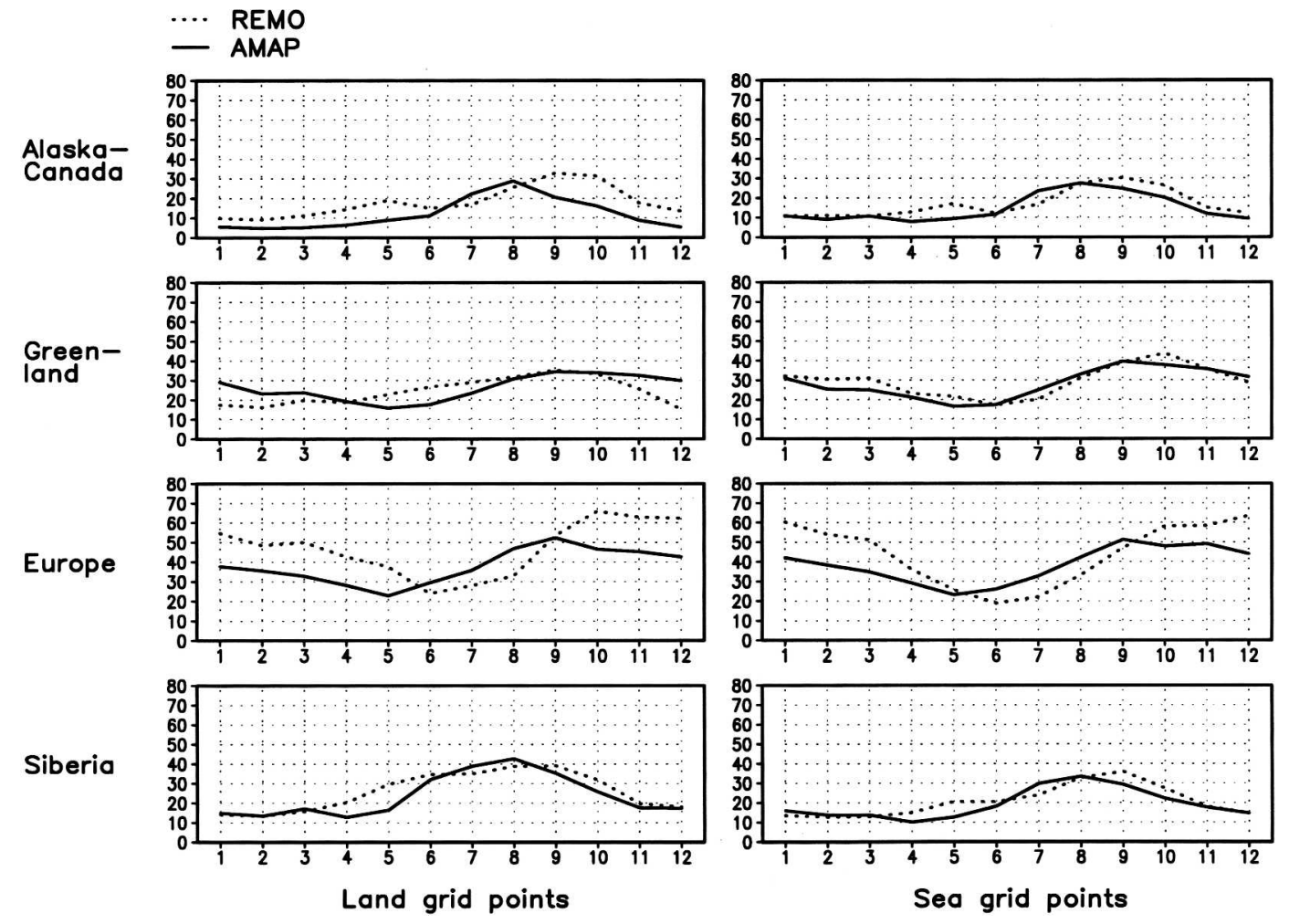

FIG. 6. Annual cycle of precipitation in $\mathrm{mm} \mathrm{month}^{-1}$ from REMO 5.1 and AMAP. Time period for REMO 5.1 is 1979-2000, and time period for AMAP is 1950-99.

with

- $F_{W}$ : water flux across $70^{\circ} \mathrm{N}\left(\mathrm{kg} \mathrm{s}^{-1}\right)$;

- $v$ : south-north component of the wind $\left(\mathrm{m} \mathrm{s}^{-1}\right)$;

- $q_{v}$ : water vapor content $\left(\mathrm{kg} \mathrm{kg}^{-1}\right)$;

- $q_{w}$ : liquid and ice water content $\left(\mathrm{kg} \mathrm{kg}^{-1}\right)$;

- $x$ : distance in west-east direction at $70^{\circ} \mathrm{N}(\mathrm{m})$;

- $p$ : Pressure $(\mathrm{Pa})$;

- $g$ : acceleration due to gravity $\left(9.80665 \mathrm{~m} \mathrm{~s}^{-2}\right)$;

- $F_{E}$ : energy flux across $70^{\circ} \mathrm{N}(\mathrm{W})$;

- $c_{p}$ : specific heat of dry air at constant pressure [1005 $\left.\mathrm{J}(\mathrm{kgK})^{-1}\right]$;

- $T$ : temperature $(\mathrm{K})$;

- $L$ : latent heat of condensation $\left(2501 \times 10^{6} \mathrm{~J} \mathrm{~kg}^{-1}\right)$;

- $z$ : geopotential height $(\mathrm{m})$; and

- $\mathbf{v}$ : wind vector $\left(\mathrm{m} \mathrm{s}^{-1}\right)$.

The uncertainty of the calculated water and energy fluxes is determined in a manner similar to that in NO88. Twice the standard deviation from the mean of each season and of the whole year is used as an estimate of the $95 \%$ confidence interval, where each season and each year of the sample of 22 yr (1979-2000) is considered.

Figure 8 shows the water fluxes from REMO 5.1 and from Serreze et al. (1995) as annual and seasonal means. The REMO 5.1 simulation period lasts from 1979 to 2000, whereas the observation period lasts from 1974 to 1991 . Thus the periods are similar but not equal. For a better comparability between surface and lateral fluxes, the lateral fluxes are normalized with the area of the domain north of $70^{\circ} \mathrm{N}$. Thus both the water fluxes at the surface and at the boundary can be given in $\mathrm{mm}$ month $^{-1}$.

The simulated water fluxes agree with the ones from Serreze et al. (1995) in all seasons within the uncertainty, which is only given for REMO 5.1 here. In the annual mean, the water flux at the surface $(P-E)$ is about $14 \mathrm{~mm}$ month $^{-1}$. Also a more recent study from Barry and Serreze (2000, hereafter BS00) reports a $P$ $E$ value of $14 \mathrm{~mm} \mathrm{month}^{-1}$ averaged over the region north of $70^{\circ} \mathrm{N}$ and values similar to Serreze et al. (1995) for the different seasons. In contrast, the $P-E$ values from the forecast system of ERA-15 and NCEP1 are as low as $11 \mathrm{~mm}$ month $^{-1}$ for ERA-15 and $9 \mathrm{~mm} \mathrm{month}^{-1}$ for NCEP1 (Bromwich et al. 2000) because of the model spinup after the initialization of the forecast system as discussed in section 1 . The water flux, $P-E$, is weakest in the winter season and increases throughout the year until autumn.

The lateral water transport is also weakest in winter 

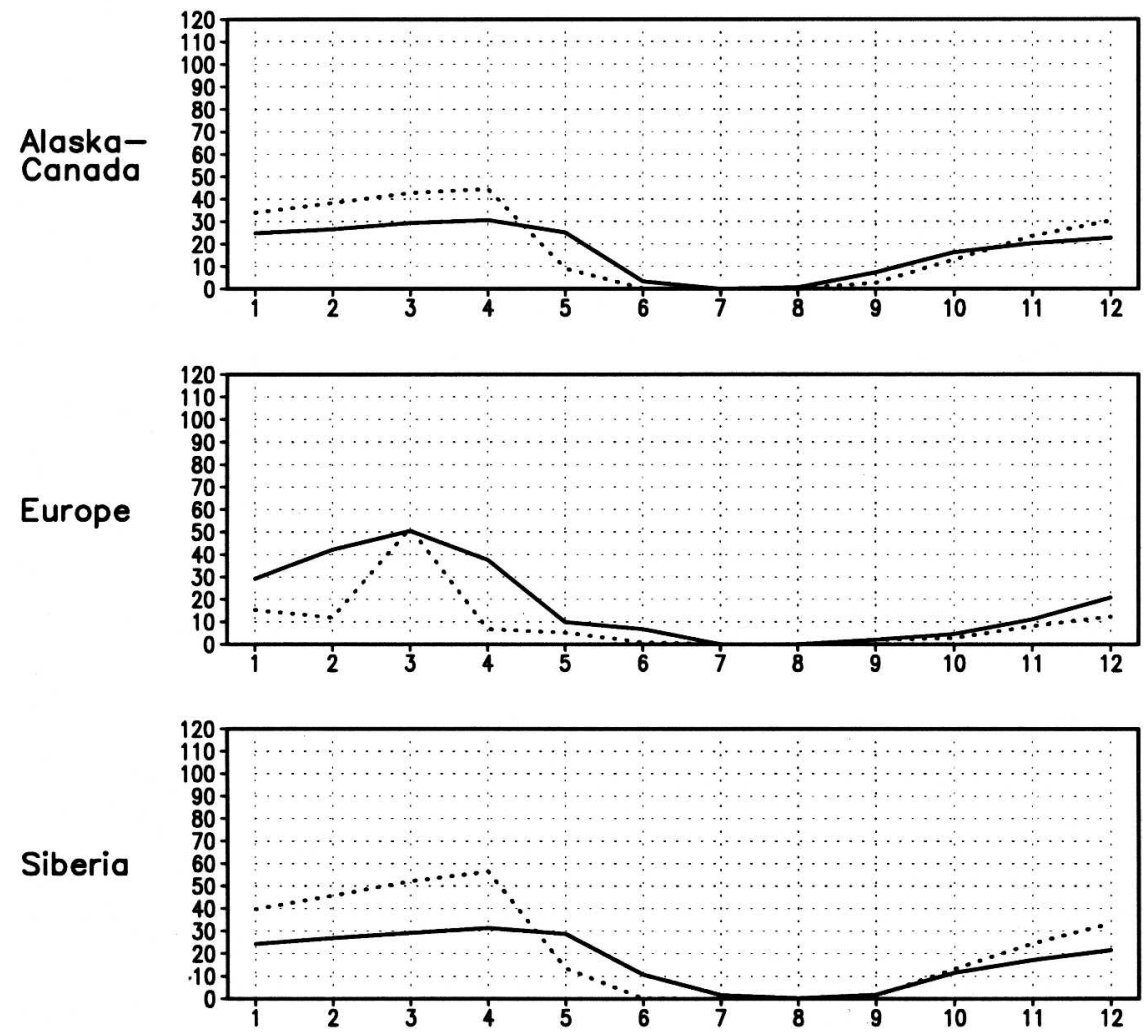

FIG. 7. Annual cycle of snow height in $\mathrm{cm}$ from REMO 5.1 and AMAP in land regions. Time period for REMO 5.1 is 1979-2000, and time period for AMAP is 1966-82.

but strongest in summer according to the REMO 5.1 simulation. Interestingly, whereas Serreze et al. (1995) report the strongest lateral water transport in autumn, Dickson et al. (2000) get the strongest transport in summer similar to the REMO 5.1 simulation, even though they use the same rawinsonde data as Serreze et al. (1995). From a synthesis of reanalysis, moisture convergence values and recent studies Cullather et al. (2000) report a yearly mean value of $15.8 \pm 1.9 \mathrm{~mm} \mathrm{month}^{-1}$ for the lateral water transport, which is somewhat higher than the REMO 5.1 value and the one from Serreze et al. (1995) but agrees within the range of uncertainty.

Tables 1 and 2 show the contributions of the single components to the water budget: water vapor and liquid water for the lateral transport as calculated from REMO 5.1 and precipitation and evaporation for the surface flux as calculated from REMO 5.1 in comparison to values from BS00. They put together a precipitation climatology from Serreze and Hurst (2000) comprising corrected gauge station values from Legates and Willmott (1990) as well as additional Russian, Canadian, and North Pole station values and a $P-E$ clima- tology from Serreze and Barry (2000) similar to the one from Serreze et al. (1995) represented in Fig. 8 but used for an extended time period (1973-95). For completeness in Table 2, the $P-E$ values are given in addition, which are the ones in Fig. 8 for REMO 5.1, but slightly different values are given for the rawinsonde-based data because of the extended time period.

As expected, the lateral liquid water transport is only a small partition of the lateral total water transport due to the larger amounts of atmospheric water vapor compared to atmospheric liquid water. Thus the lateral liquid water transport has been neglected in previous studies (Serreze et al. 1995; Cullather et al. 2000). Precipitation and evaporation are comparable between REMO 5.1 and values given by BS00, although REMO 5.1 shows a stronger hydrological cycle (more precipitation and more evaporation) compared to BSO0, except for in the summer season, in which the hydrological cycle is weaker in the REMO 5.1 simulation.

Figure 9 shows the energy fluxes from REMO 5.1 and from NO88 as annual and seasonal means. The REMO 5.1 simulation period lasts from 1979 to 2000, whereas in the observation period, data from 1963 to 


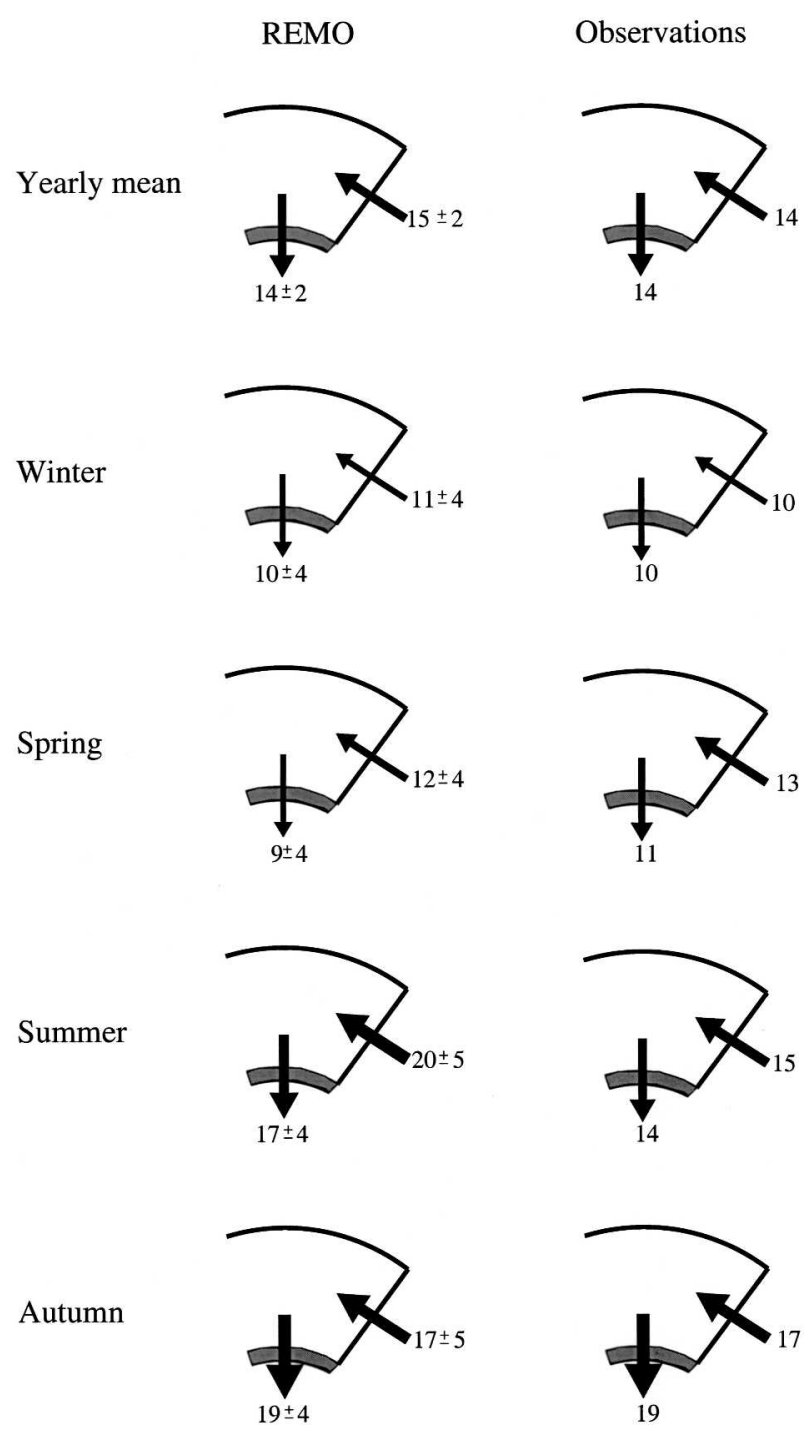

FIG. 8. Water budget of the Arctic atmosphere north of $70^{\circ} \mathrm{N}$ from REMO 5.1 and from observations according to Serreze et al. (1995). The thickness of the arrows is proportional to the intensity of the fluxes. Fluxes are given in $\mathrm{mm} \mathrm{month}^{-1}$. Time period for REMO 5.1 is $1979-2000$, and time period for observations is 1974 91.

1977 are included. The periods are quite different; they do not even overlap. Similar to the lateral water fluxes, the lateral energy fluxes are normalized with the area of the domain north of $70^{\circ} \mathrm{N}$. All fluxes are given in $\mathrm{W}$ $\mathrm{m}^{-2}$.

Even though the time periods of observations and simulations are different, most fluxes agree within the uncertainties of observations and simulation. In the annual mean, the emission of energy at the top of the atmosphere is roughly $100 \mathrm{~W} \mathrm{~m}^{-2}$ (Fig. 9, top). This is mainly compensated for by the lateral transport. In addition, the ocean contributes to the poleward energy
TABLE 1. Components of lateral water fluxes across $70^{\circ} \mathrm{N}$ from REMO 5.1 in mm month ${ }^{-1}$.

\begin{tabular}{lcc}
\hline & Water vapor & Liquid water \\
\hline Year & 15 & 0.3 \\
Winter & 11 & 0.3 \\
Spring & 12 & 0.2 \\
Summer & 19 & 0.3 \\
Autumn & 17 & 0.3 \\
\hline
\end{tabular}

transport by the transport of warm water into the Arctic. At the same time, sea ice is transported out of the Arctic leading to a slightly upward-directed energy transport at the surface. In autumn and winter, the Arctic atmosphere emits a lot of energy at the top, whereas in summer, outgoing and incoming radiation fluxes are roughly balanced. In all seasons beside summer, the surface releases energy to the atmosphere. In summer the surface takes up a lot of energy from the atmosphere. In winter and summer, the three energy fluxes are balanced. Thus the total amount of energy in the Arctic atmosphere stays constant during these two seasons. In spring the Arctic atmosphere gains energy; in autumn it loses energy. The lateral transport of energy is quite constant during all seasons compared to the transports at the top and at the surface.

In Tables 3, 4, and 5, the single components of the energy fluxes from REMO and-as far as availablefrom previous studies are given. At the top of the atmosphere, the absolute values of both the shortwave and the longwave radiation are mostly higher in REMO 5.1 than in NO88 from satellite data. Whereas-not surprisingly - the shortwave radiation shows a strong annual cycle with maximum values in summer, the annual cycle of the longwave radiation is clearly weaker.

The lateral energy fluxes across $70^{\circ} \mathrm{N}$ from REMO 5.1 can be compared to values given by OT94 except for the kinetic energy, which is not included by Overland and Turet but which does not contribute significantly to the lateral energy fluxes according to the REMO 5.1 results. For completeness in Table 4, the sum of lateral energy fluxes is also given, the values of which are from

TABLE 2. Components of surface water fluxes north of $70^{\circ} \mathrm{N}$ from REMO 5.1 and from BS00 in mm month ${ }^{-1}$.

\begin{tabular}{|c|c|c|c|c|c|c|}
\hline & \multicolumn{2}{|c|}{ Precipitation } & \multicolumn{2}{|c|}{ Evaporation } & \multicolumn{2}{|c|}{$P-E$} \\
\hline & REMO & BS00 & REMO & BS00 & REMO & BS00 \\
\hline Year & 25 & 23 & 12 & 10 & 14 & 14 \\
\hline Winter & 23 & 19 & 12 & 10 & 10 & 10 \\
\hline Spring & 21 & 16 & 12 & 6 & 9 & 11 \\
\hline Summer & 25 & 29 & 8 & 13 & 17 & 16 \\
\hline Autumn & 33 & 29 & 14 & 10 & 19 & 18 \\
\hline
\end{tabular}




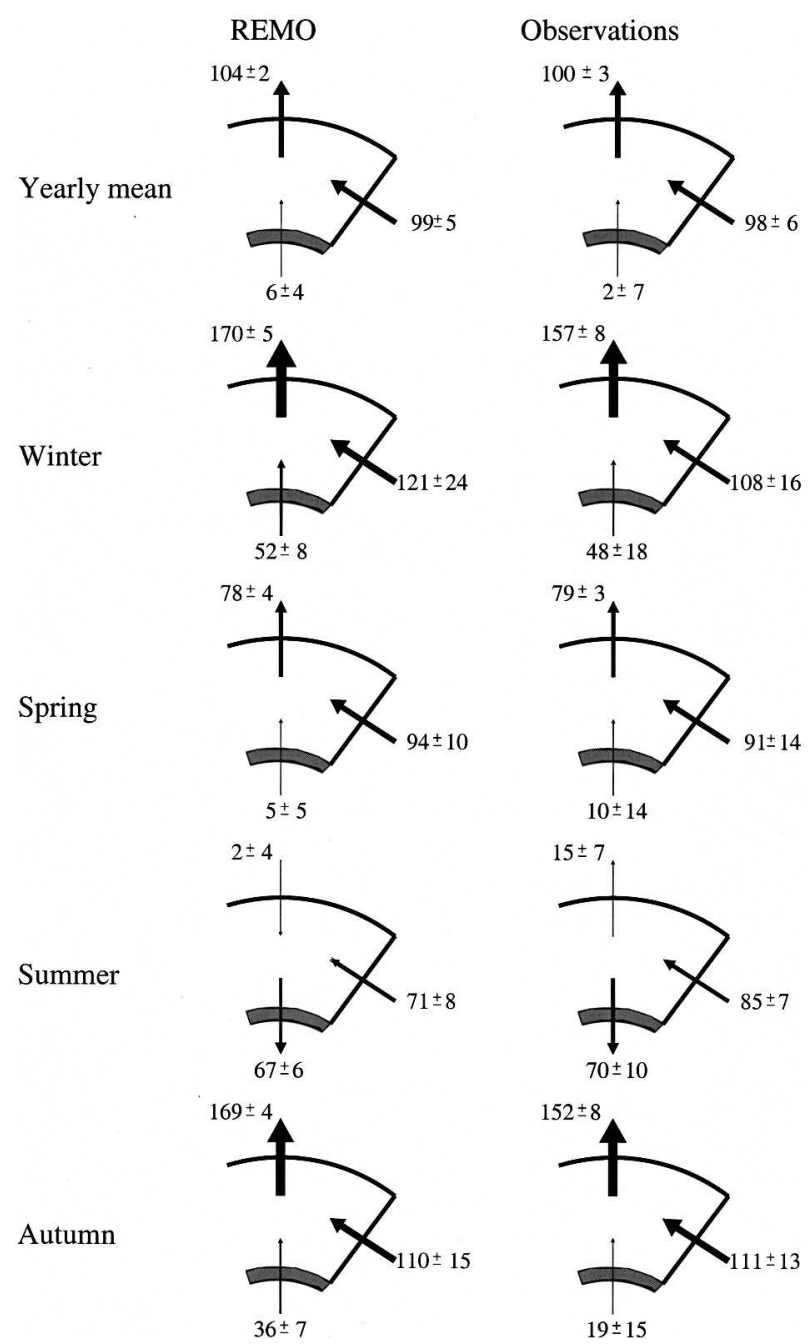

FIG. 9. Energy budget of the Arctic atmosphere north of $70^{\circ} \mathrm{N}$ from REMO 5.1 and from observations according to NO88. The thickness of the arrows is proportional to the intensity of the fluxes. Fluxes are given in $\mathrm{W} \mathrm{m}^{-2}$. Time period for REMO 5.1 is 1979-2000, and time period for observations is 1963-77.

Fig. 9 for REMO 5.1 and are very similar between OT94 and NO88, since the more recent study is an extension of the climatology given in the older one. Even if the sum is very similar between REMO 5.1 results and both observational studies, there are some differences in the single components: the transport of sensible and latent heat is larger in REMO 5.1 compared to OT94, whereas the opposite is true for the potential energy. These differences could be caused by the different time periods. While OT94 consider a time period of 1965-89, in our study the years 1979-2000 are included. Thus in our study, more years with high NAO index are included compared to the one from Overland and Turet (see Fig. 2). In section 5, it is shown that in winters with high NAO indexes, the lateral transport of
TABLE 3. Components of energy fluxes at the top of the atmosphere north of $70^{\circ} \mathrm{N}$ from REMO 5.1 and from NO88 in $\mathrm{W} \mathrm{m}{ }^{-2}$.

\begin{tabular}{lccccc}
\hline \hline & \multicolumn{2}{c}{ Shortwave radiation } & & \multicolumn{2}{c}{ Longwave radiation } \\
\cline { 2 - 3 } \cline { 6 - 6 } & REMO & NO88 & & REMO & NAO \\
\hline Year & 94 & 79 & & -198 & -179 \\
Winter & 2 & 2 & & -172 & -158 \\
Spring & 119 & 97 & & -197 & -177 \\
Summer & 231 & 192 & & -230 & -209 \\
Autumn & 24 & 25 & & -193 & -174 \\
\hline
\end{tabular}

sensible and latent heat seems to be increased, whereas the transport of potential energy seems to be reduced. However, this should be further investigated since the sample of NAO high and low winters is small in our study.

At the surface the most important contributors to the energy flux are the radiation fluxes, although during the polar night the shortwave radiation flux is 0 . The annual cycle of the shortwave radiation determines the annual cycle of the total energy flux, since the longwave radiation, the sensible heat flux, the latent heat flux and the melting energy do not vary very much during the year or are of minor importance.

Some differences between model results and observations in the components of the water and energy fluxes should be summarized here: The downward shortwave radiation at the surface is underestimated in our simulation compared to observations, whereas at the top of the atmosphere the absolute values of both the net shortwave and the net longwave radiation are overestimated. There seems to be more liquid water in the atmosphere, and the hydrological cycle is more pronounced. In addition, the lateral sensible and latent heat transport is larger, whereas the lateral transport of potential energy is smaller in REMO 5.1 compared to the observational studies. Some of these differences could be due to the comparison of different time periods, since our simulation includes more recent years compared to the observational studies.

Differences between measured and simulated total energy fluxes occur in summer, when observations show a slightly outgoing energy flux, whereas the simulations show a flux close to 0 at the top of the atmosphere. In autumn the energy emission at the top of the atmosphere is larger in the simulation compared to the observations.

Despite the differences in the components of the water and energy fluxes, the similarity of simulated and observed total water and energy fluxes is quite striking. Even though different periods are covered and different methods are used in the previous studies and in this 
TABLE 4. Components of lateral energy fluxes across $70^{\circ} \mathrm{N}$ from REMO 5.1 and from OT94 in $\mathrm{W} \mathrm{m}^{-2}$.

\begin{tabular}{|c|c|c|c|c|c|c|c|c|c|}
\hline & \multicolumn{2}{|c|}{ Sensible heat } & \multicolumn{2}{|c|}{ Latent heat } & \multicolumn{2}{|c|}{ Potential energy } & \multirow{2}{*}{$\frac{\text { Kinetic energy }}{\text { REMO }}$} & \multicolumn{2}{|c|}{ Sum } \\
\hline & REMO & OT94 & REMO & OT94 & REMO & ОТ94 & & REMO & OT94 \\
\hline Year & 60 & 44 & 14 & 11 & 25 & 48 & -0.2 & 99 & 103 \\
\hline Winter & 88 & 68 & 11 & 8 & 23 & 44 & -0.5 & 121 & 121 \\
\hline Spring & 58 & - & 11 & - & 25 & - & -0.4 & 94 & - \\
\hline Summer & 23 & 21 & 18 & 17 & 30 & 47 & 0.1 & 71 & 85 \\
\hline Autumn & 71 & - & 16 & - & 23 & - & -0.1 & 110 & - \\
\hline
\end{tabular}

study, the results for the total fluxes are very similar. Thus the climatological water and energy fluxes can be assumed to be robust. The Arctic is a sink for water (to the ocean) and energy (to space and ocean) advected from midlatitudes. Even if there are still some shortcomings in the simulation, which should be further investigated and reduced by improved parameterizations, our approach gives directly calculated fluxes for the surface rather than residual values, as from observations, or strongly biased fluxes, as from forecasts of the reanalysis system. In addition, the whole time period and area are covered in the same resolution with simulation data. The model delivers consistent data, which can be seen as reanalyses in a high resolution. Furthermore, it has turned out that there is no significant model drift over the 22-yr-long REMO 5.1 simulation. The water and energy budget is closed, as can be seen in Figs. 8 and 9, where in the yearly mean the fluxes are balanced within the uncertainties. Thus, the total water and energy content of the Arctic atmosphere stays approximately constant during the simulation apart from seasonal variations.

\section{Dependence of budgets on the NAO}

To determine the influence of the NAO on the water and energy budget of the Arctic atmosphere, composites are formed for different periods of the NAO. Three periods with the lowest NAO index between December and March (hereafter referred to as extended winters) and three periods with the highest NAO index between 1979 and 2001 are chosen. According to the method of

TABLE 5. Components of surface energy fluxes north of $70^{\circ} \mathrm{N}$ from REMO 5.1 in $\mathrm{W} \mathrm{m}^{-2}$.

\begin{tabular}{lccccc}
\hline \hline & $\begin{array}{c}\text { Shortwave } \\
\text { radiation }\end{array}$ & $\begin{array}{c}\text { Longwave } \\
\text { radiation }\end{array}$ & $\begin{array}{c}\text { Sensible } \\
\text { heat flux }\end{array}$ & $\begin{array}{c}\text { Latent } \\
\text { heat flux }\end{array}$ & $\begin{array}{c}\text { Melting } \\
\text { energy }\end{array}$ \\
\hline Year & 42 & -34 & -3 & -11 & -1 \\
Winter & 0 & -38 & -3 & -12 & 0 \\
Spring & 48 & -39 & -1 & -12 & -2 \\
Summer & 113 & -33 & -6 & -7 & -1 \\
Autumn & 8 & -28 & -1 & -13 & 0 \\
\hline
\end{tabular}

determination of the NAO index described in Jones et al. (1997), these periods are the extended winters 1984/ $85(-0.4), 1995 / 96(-2.3)$, and 2000/01 $(-0.5)$ for low NAO and 1988/89 (+2.9), 1989/90 (+2.4), and 1994/95 (+2.4) for high NAO (Fig. 2).

Figure 10 shows the water and energy fluxes as a composite of the three extended winters with low and high NAO indexes, respectively. The given uncertainties are twice the standard deviation of the extended winters based on the whole simulation period because it is not possible to determine a standard deviation from only three values. A longer simulation period with more cases of low and high NAO or ensemble simulations would be necessary to determine the dependence of the water and energy fluxes on the NAO with more reliability and to give reasonable values for the uncertainty. But even if extending the simulation period to 40 $\mathrm{yr}$, the sample size on a seasonal basis would not be satisfactory. It would be either necessary to take into account also winters with lower absolute values of the NAO index as done by Rogers et al. (2001) or to look at daily composites of high and low NAO indexes as done by Groves and Francis (2002) for the AO to get reasonable sample sizes.

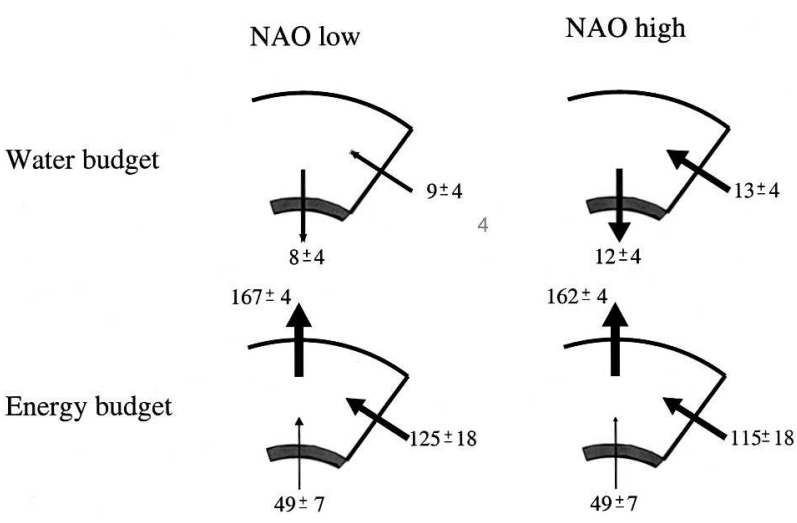

FIG. 10. Water and energy budget of the Arctic atmosphere north of $70^{\circ} \mathrm{N}$ as a mean over three periods from Dec to Mar with low NAO indexes and three corresponding periods with high NAO indexes. The uncertainties are based on the whole simulation period (low and high NAO indexes). 
Despite the small number of cases, some features should be mentioned here. The water budget does not seem to be dependent on the NAO if taking into account the large uncertainties. The surface and lateral fluxes are about $50 \%$ larger for NAO high than for NAO low in our simulation (Fig. 10), but the differences are within the uncertainties. Nevertheless, Rogers et al. (2001) and Dickson et al. (2000) also report increased $P-E$ for winters with positive NAO index compared to winters with negative NAO index. Dickson et al. (2000) give values for the lateral water fluxes across $70^{\circ} \mathrm{N}$ : $13 \mathrm{~mm}$ month $^{-1}$ for winters with high NAO indexes and $7 \mathrm{~mm}$ month $^{-1}$ for winters with low NAO indexes. Unfortunately, the considered time period in the study of Dickson et al. (2000) is even shorter compared to our study. It comprises the years 1974-91. In addition, their values are not directly comparable to ours, since we included March. But still the values are similar to ours, although they indicate a larger difference between NAO high and low. Even larger differences in the lateral moisture fluxes appear if looking at daily AO high and low composites (Groves and Francis 2002), probably because daily composites will comprise more extreme values for the indexes than seasonal ones. In the winter season for AO high, the lateral moisture flux across $70^{\circ} \mathrm{N}$ is 6 times larger than for $\mathrm{AO}$ low. On the other hand, on a daily basis, the $P-E$ differences are much smaller than the moisture flux differences and account for $50 \%$. Thus the $P-E$ differences on a daily basis are similar to our results on a seasonal basis. Since NAO and AO are closely linked (e.g., Rogers et al. 2001), it is probable that similar differences will appear if looking at daily NAO high and low composites.

If the Arctic is divided into the four regions according to Fig. 1, the European region shows the strongest increase of $P-E$ for NAO high compared to NAO low on the water budget (Fig. 11), which is consistent with several previous studies (e.g., Dickson et al. 2000; Rogers et al. 2001; Groves and Francis 2002). But even in this region, the differences are within the large uncertainties. The uncertainty is most pronounced in the European region because it is calculated as twice the standard deviation from the whole simulation period and thus includes the variability due to different large-scale circulation types, which is largest in the European region. Because of the limited number of cases, it is not possible to calculate the uncertainty for NAO index high and low cases separately. The surface water flux is $-3 \pm 13 \mathrm{~mm} \mathrm{month}^{-1}$ for NAO low and $11 \pm 13 \mathrm{~mm}$ month $^{-1}$ for NAO high. This means that for low NAO indexes, precipitation is less than evaporation in the Eu-
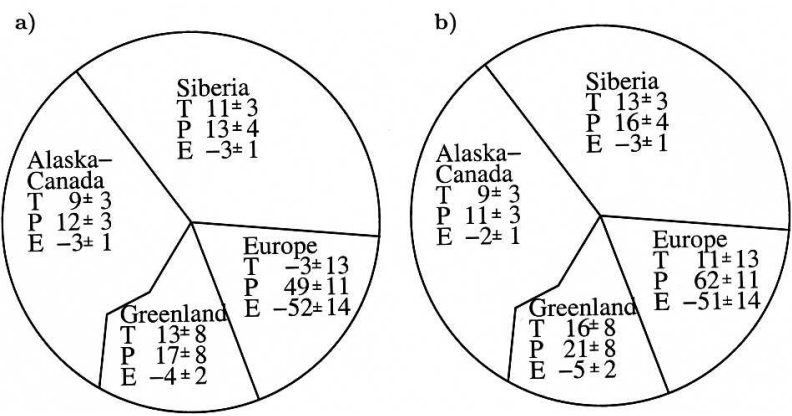

FIG. 11. Surface water budget of the Arctic atmosphere north of $70^{\circ} \mathrm{N}$ as a mean over (a) three periods from Dec to Mar with low $\mathrm{NAO}$ indexes and (b) three corresponding periods with high NAO indexes for the four regions in Fig. 1. The uncertainties are based on the whole simulation period (low and high NAO indexes); $T$ is the total surface water flux consisting of precipitation $(P)$ and evaporation $(E)$. Fluxes are defined positive downward.

ropean region. The precipitation is $49 \pm 11 \mathrm{~mm} \mathrm{month}^{-1}$ for NAO low and $62 \pm 11 \mathrm{~mm} \mathrm{month}^{-1}$ for NAO high, which is plausible because of the transport of moist air from the North Atlantic region into the European Arctic for NAO high. The evaporation remains unchanged.

The influence on the Arctic energy budget by the NAO is also within the uncertainties (Fig. 10), and for the energy budget, the differences are even smaller compared to the water budget, which is consistent with a study by Adams et al. (2000), who report only a small influence of the AO on the Arctic energy budget. Even if looking at the subdomains, the differences remain within the uncertainty (not shown). Because there is more transport of water vapor into the European Arctic in cases with NAO high compared with NAO low, the lateral latent heat transport is also larger $(12 \pm 4 \mathrm{~W}$ $\mathrm{m}^{-2}$ for NAO high and $9 \pm 4 \mathrm{~W} \mathrm{~m}^{-2}$ for NAO low). But in the extended winters (mean over 1979-2000), the lateral latent heat transport from the midlatitudes into the Arctic accounts for only $9 \%$ of the total lateral energy transport and thus plays a secondary role. The lateral transports of sensible heat $(74 \%)$ and potential energy $(17 \%)$ are more important. The lateral transport of kinetic energy is close to 0 . The larger lateral latent heat transport and a larger lateral sensible heat transport for NAO high $\left(93 \pm 56 \mathrm{~W} \mathrm{~m}^{-2}\right)$ compared with NAO low $\left(62 \pm 56 \mathrm{~W} \mathrm{~m}^{-2}\right)$ are compensated for by a smaller lateral transport of potential energy (10 \pm $47 \mathrm{~W} \mathrm{~m}^{-2}$ for NAO high and $54 \pm 47 \mathrm{~W} \mathrm{~m}^{-2}$ for $\mathrm{NAO}$ low).

In summary, the influence of the NAO on the lateral water fluxes into the Arctic and the surface water fluxes remains within the large uncertainties. If not considering uncertainties, the conclusion would look different 
and comparable to previous studies, in which enhanced $P-E$ values and lateral moisture fluxes for NAO high compared to NAO low with the largest differences in the European Arctic are reported. Within the European Arctic, the evaporation remains unchanged, while the amount of precipitation is larger for NAO high than for NAO low. The energy fluxes are not influenced by the NAO above their uncertainties either. In addition, the differences in the energy fluxes are mostly smaller than the ones in the water fluxes, consistent with the results of previous studies. Single components of the lateral energy fluxes differ, but the uncertainties are still larger than the differences.

\section{Conclusions}

In this study, the water and energy budgets of the Arctic atmosphere north of $70^{\circ} \mathrm{N}$ have been investigated with the regional climate model REMO 5.1. The available reanalyses have been compared for the Arctic region with independent observations. It has been shown, that the 15-yr ECMWF reanalyses perform better in the Arctic region than both NCEP reanalyses. Thus, the ECMWF reanalyses have been used to drive REMO 5.1 at the lateral boundaries, even though it was necessary to combine these data with ECMWF analyses data for the recent years. The comparison of REMO 5.1 results with climatological values of precipitation, snow height over land, 2-m temperature, and shortwave radiation of the Arctic Meteorology and Climate Atlas (Fetterer and Radionov 2000) has shown that REMO 5.1 is generally able to simulate the Arctic climate, even though some differences appear.

The surface water and energy fluxes, and the energy flux at the top of the atmosphere north of $70^{\circ} \mathrm{N}$ as well as the lateral water and energy fluxes across $70^{\circ} \mathrm{N}$, have been calculated from model simulation results as climatological seasonal and annual means for 1979-2000. Although there are still some shortcomings in Arctic climate simulations in general and in the REMO 5.1 simulation specifically, the regional climate approach has turned out to be a suitable method to investigate the Arctic water and energy budget. One consistent method has been used to calculate all fluxes rather than combining different data sources. Most previous studies report problems in determining the surface fluxes. Because of the lack of direct observations, the surface fluxes had to be determined either as residual values bearing a large uncertainty or from reanalysis data, from which those parameters are biased, because they are taken from the reanalysis forecast models and thus affected by model spinup and not directly assimilated with observations. Furthermore, it has turned out that there is no significant model drift over the 22-yr-long REMO 5.1 simulation. The water and energy budget is closed within the uncertainties, and the total water and energy content stays approximately constant during the simulation.

The simulated annual and seasonal climatological total water and energy fluxes agree in most cases with the ones derived from observations within the uncertainties of the observations and even the model, so the time periods are different. However, when looking at single components rather than at the total fluxes, some differences appear: The downward shortwave radiation at the surface is underestimated in our simulation compared to observations, whereas at the top of the atmosphere the absolute values of both the net shortwave and the net longwave radiation are overestimated. This could indicate a too-large atmospheric water content in our model simulation. It has also turned out that the hydrological cycle is more intense in REMO 5.1 compared to observations. In addition, the lateral sensible and latent heat transport is larger, whereas the lateral transport of potential energy is smaller in REMO 5.1 compared to the observational studies. These differences could be partly due to insufficient model parameterizations and partly connected with different time periods. Whereas in our study the most recent years are considered, the observational studies use mostly earlier years.

The overall agreement of the total water and energy fluxes allows two conclusions: the fluxes are well quantified and have a high reliability. At the surface, the uncertainty is reduced by using the model simulation, because the surface fluxes can be calculated directly instead of determining them as a residuum or from the reanalysis forecast model.

The influence of the North Atlantic Oscillation (NAO) has been investigated using composites of the simulation results of three extended winters (December-March) with a low NAO index and three extended winters with a high NAO index. The sample of only three winters with low NAO index and high NAO index is very small, leads to a high uncertainty in the results, and should be enlarged in future investigations by extending the simulation period or using ensemble simulations. This should be considered in the interpretation of the results.

No significant dependencies could be discovered for the fluxes on NAO because of the large uncertainties. However, there is an enhanced lateral water transport into the European Arctic and a larger amount of precipitation in the European Arctic in cases with high NAO index compared with low NAO index, consistent 
with previous studies, but the uncertainties are larger than the differences in our study. There is a tendency of more lateral latent heat transport into the European Arctic in cases with high NAO compared with low NAO. However, the lateral latent heat transport plays with $9 \%$ of the total lateral energy transport averaged over the whole domain north of $70^{\circ} \mathrm{N}$ and over all extended winters only a secondary role. There also is more lateral sensible heat transport especially into the European Arctic in situations with high NAO compared to situations with low NAO. This is compensated for by less transport of potential energy.

The dependency of the fluxes on the NAO index needs further investigation by extending the time series and increasing the number of high/low NAO index extended winters for the composite. The investigation for present climate leads to the next step where the water and energy fluxes in a future climate with enhanced greenhouse gas concentrations are to be investigated. If the large-scale circulation will change in a future climate, this can have major impacts on the water and energy budget of the Arctic atmosphere. Even though average fluxes might be little influenced by different NAO indexes, the longitudinal distribution seems to change. In addition, changes in the sea ice cover in the Arctic as observed might have a feedback to midlatitude climate, as preliminary results with REMO 5.1 show (Semmler 2002).

Acknowledgments. We thank the Model and Data Group of the Max Planck Institute for Meteorology in Hamburg for supplying the ECMWF reanalyses data. The NCEP reanalysis data have been provided by the NOAA-CIRES Climate Diagnostics Center, Boulder, Colorado (available from their Web site at http://www. cdc.noaa.gov/). The whole study has been supported by the Deutsche Forschungsgemeinschaft within the Sonderforschungsbereich (SFB) 512 "Cyclones and the North Atlantic Climate System."

\section{REFERENCES}

Adams, J. M., N. A. Bond, and J. E. Overland, 2000: Regional variability of the Arctic heat budget in fall and winter. $J$. Climate, 13, 3500-3510.

Alissow, B. P., 1954: Die Klimate der Erde. Deutscher Verlag der Wissenschaften, $277 \mathrm{pp}$.

Barry, R. G., and M. C. Serreze, 2000: Atmospheric components of the Arctic Ocean freshwater balance and their interannual variability. The Freshwater Budget of the Arctic Ocean, E. L. Lewis, Ed., Kluwer Academic, 45-56.

,-- J. J. Maslanik, and R. H. Preller, 1993: The Arctic sea ice climate system: Observations and modelling. Rev. Geophys. Space Phys., 31, 397-422.

Bromwich, D. H., R. I. Cullather, and M. C. Serreze, 2000: Re- analyses depictions of the Arctic atmospheric moisture budget. The Freshwater Budget of the Arctic Ocean, E. L. Lewis, Ed., Kluwer Academic, 163-196.

Cullather, R. I., D. H. Bromwich, and M. C. Serreze, 2000: The atmospheric hydrologic cycle over the Arctic basin from reanalyses. Part I: Comparison with observations and previous studies. J. Climate, 13, 923-937.

Dickson, R. R., and Coauthors, 2000: The Arctic Ocean response to the North Atlantic Oscillation. J. Climate, 13, 2671-2696.

Fetterer, F., and V. Radionov, Eds., 2000: Environmental Working Group Arctic Meteorology and Climate Atlas. National Snow and Ice Data Center, CD-ROM.

Gibson, J. K., P. Kållberg, S. Uppala, A. Hernandez, A. Nomura, and E. Serrano, 1997: ERA description. ECMWF ReAnalysis Project Report Series 1, 86 pp.

Groisman, P. Y., V. V. Koknaeva, T. A. Belokrylova, and T. R. Karl, 1991: Overcoming biases of precipitation measurement: A history of the USSR experience. Bull. Amer. Meteor. Soc., 72, 1725-1733.

Groves, D. G., and J. A. Francis, 2002: Variability of the Arctic atmospheric moisture budget from TOVS satellite data. $J$. Geophys. Res., 107, 4785, doi:10.1029/2002JD002285.

Hagemann, S., and L. Dümenil-Gates, 2001: Validation of the hydrological cycle of ECMWF and NCEP reanalyses using the MPI hydrological discharge model. J. Geophys. Res., 106 (D2), 1503-1510.

Hurrell, J. W., 1995: Decadal trends in the North Atlantic Oscillation: Regional temperatures and precipitation. Science, 269, 676-679.

Jacob, D., 2001: A note to the simulation of the annual and interannual variability of the water budget over the Baltic Sea drainage basin. Meteor. Atmos. Phys., 77, 61-73.

— Climate Model REMO. Meteor. Atmos. Phys., 63, 119-129.

$\_,-$, and M. Claussen, 1995: REMO-A model for climate research and weather prediction. Int. Workshop on LimitedArea and Variable Resolution Models, Beijing, China, WMO, 273-278.

— , and Coauthors, 2001: A comprehensive model intercomparison study investigating the water budget during the BALTEX-PIDCAP period. Meteor. Atmos. Phys., 77, 19-43.

Jones, P. D., T. Jonsson, and D. Wheeler, 1997: Extension to the North Atlantic Oscillation using early instrumental pressure observations from Gibraltar and South-West Iceland. Int. J. Climatol., 17, 1433-1450.

Kalnay, E., and Coauthors, 1996: The NCEP/NCAR 40-Year Reanalysis Project. Bull. Amer. Meteor. Soc., 77, 437-471.

— , R. Kistler, and M. Kanamitsu, 1998: NCEP/NCAR 40-Year Reanalysis Project overview. Proc. First Int. Conf. on Reanalyses, Silver Spring, MD, World Climate Research Programme, 1-7.

Kanamitsu, M., W. Ebisuzaki, J. Woollen, S.-K. Yang, J. J. Hnilo, M. Fiorino, and G. L. Potter, 2002: NCEP-DOE AMIP-II Reanalysis (R-2). Bull. Amer. Meteor. Soc., 83, 1631-1643.

Legates, D., and C. Willmott, 1990: Mean seasonal and spatial variability in gauge-corrected global precipitation. Int. J. Climatol., 10, 110-127.

Martyn, D., 1992: Climates of the World. Developments in Atmospheric Science. Monogr., No. 18, Elsevier, 435 pp.

Nakamura, N., and A. Oort, 1988: Atmospheric heat budgets of the polar regions. J. Geophys. Res., 93 (D8), 9510-9524.

Overland, J. E., and P. Turet, 1994: Variability of the Atmo- 
spheric Energy Flux across $70^{\circ} \mathrm{N}$ computed from the GFDL data set. Nansen Centennial Volume, Geophys. Monogr., No. 84, Amer. Geophys. Union, 313-325.

- _ static energy flux into the Arctic. J. Climate, 9, 54-65.

Polar Group, 1980: Polar atmosphere-ice-ocean processes: A review of polar problems in polar research. Rev. Geophys. Space Phys., 18, 525-543.

Rogers, A. N., D. H. Bromwich, E. N. Sinclair, and R. I. Cullather, 2001: The atmospheric hydrologic cycle over the Arctic basin from reanalyses. Part II: Interannual variability. $J$. Climate, 14, 2414-2429.

Semmler, T., 2002: Der Wasser- und Energiehaushalt der arktischen Atmosphäre. Examensarbeit 85, Max Planck Institute for Meteorology, Hamburg, Germany, 106 pp.

, D. Jacob, K. H. Schlünzen, and R. Podzun, 2004: Influence of sea ice treatment in a regional climate model on boundary layer values in the Fram Strait region. Mon. Wea. Rev., 132, 985-999.

Serreze, M. C., and R. G. Barry, 2000: Atmospheric components of the Arctic Ocean hydrologic budget assessed from rawinsonde data. The Freshwater Budget of the Arctic Ocean, E. L. Lewis, Ed., Kluwer Academic, 141-162.

- and C. M. Hurst, 2000: Representation of mean Arctic precipitation from NCEP-NCAR and ERA reanalyses. J. Climate, 13, 182-201.

_ , R. G. Barry, and J. E. Walsh, 1995: Atmospheric water vapor characteristics at $70^{\circ}$ N. J. Climate, 8, 719-731.

_ J. R. Key, J. E. Box, J. A. Maslanik, and K. Steffen, 1998: A new monthly climatology of global radiation for the Arctic and comparisons with NCEP-NCAR reanalysis and ISCCPC2 fields. J. Climate, 11, 121-136.

Wagner, H., 1912: Lehrbuch der Geographie. 9th ed. Hahnsche Buchhandlung, 1022 pp. 